Health \& Medicine | Sonja Schrepfer \& Tobias Deuse

\section{A new generation of induced pluripotent stem cells for regenerative medicine}

\begin{tabular}{|c|c|}
\hline $\begin{array}{l}\text { Embryonic stem cells or } \\
\text { induced pluripotent stem cells } \\
\text { are unlimited sources for the } \\
\text { generation of cell derivatives } \\
\text { for the regeneration of failing } \\
\text { organs. However, such cell } \\
\text { transplants are subject to } \\
\text { immune rejection by the } \\
\text { recipient's immune system. } \\
\text { Drs Sonja Schrepfer and Tobias } \\
\text { Deuse from the University of } \\
\text { California, San Francisco, have } \\
\text { developed a new generation } \\
\text { of immune-edited induced } \\
\text { pluripotent stem cells that } \\
\text { could constitute a source } \\
\text { of universally compatible } \\
\text { cell products. }\end{array}$ & 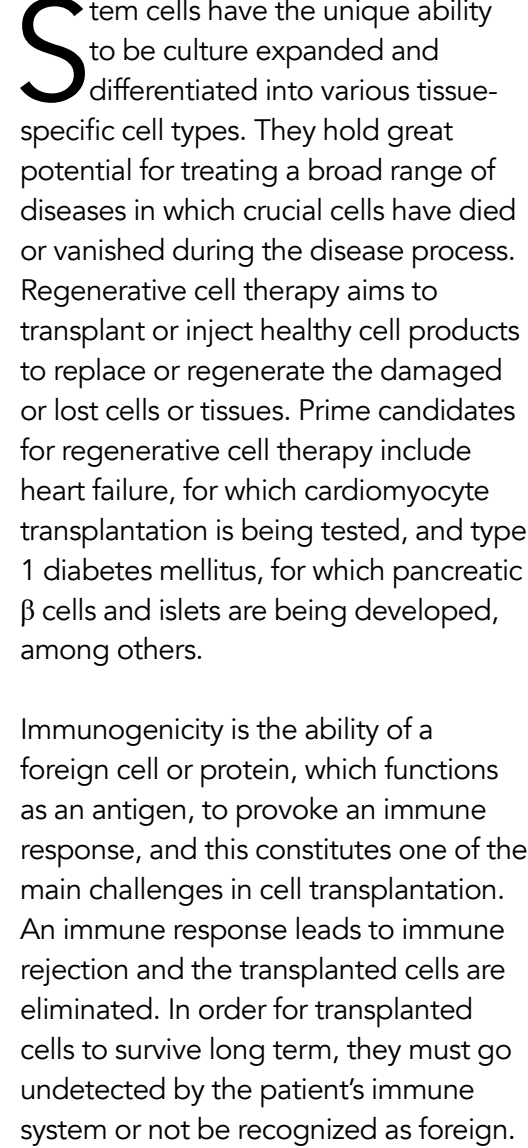 \\
\hline
\end{tabular}

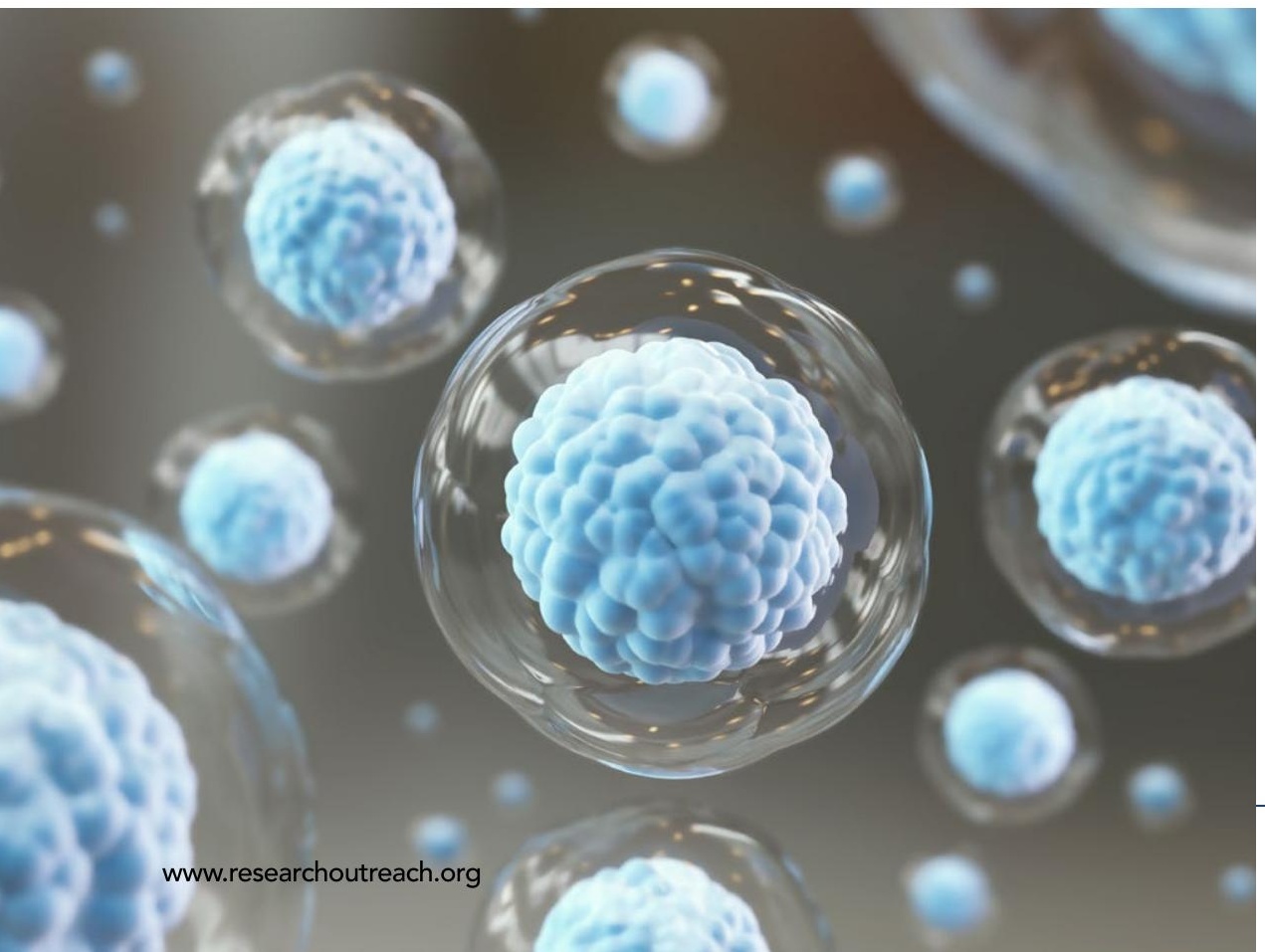

In their early work, Dr Schrepfer and Dr Deuse showed that embryonic stem cells, which were initially thought to be a very promising source of less immunogenic cells for therapy, could induce an immun esponse

\section{THE LIMITS OF}

\section{EMBRYONIC STEM CELLS}

Embryonic stem cells (ESCs) are derived at an early developmenta stage, before the time that implantatio would normally occur in the uterus.

ESCs can differentiate into multiple adult

or neurons.

Major histocompatibility complex (MHC) molecules are cell surface proteins that play a key role in immune recognition. These proteins are highly polymorphic and present endogenous peptides to foreign antigens, an immune response against the cells is induced and the cells undergo cylotoxic kiling. ESCs have ben shoun to expess low levels or MHC to evade the immune system.

However, Dr Schrepfer's group showed that the low levels of immunogenicityrelated molecules expressed on ESCS were still sufficient to trigger an immune response and result in rejection'. Sun
of transplanted ESCs, however, was a functional immune system ${ }^{2}$. This semina early work drew the attention of the stem subsequent immunology research related to stem cells and regenerative therapy.

MINOR HISTOCOMPATIBILITY ANTIGENS

DrSchrepfer and Dr Deuse revealed

that minor histocompatibility antigens cell types in vitro, such as cardiac cells immune cells. If immune cells recognise achieved in immunodeficient mice lacking cell community and sparked much of the
( $m$ HAs) can emerge as transplantelevant antigens in the context of ce ransplantation. Some mH As can be ystem and induce an inmune response even without $\mathrm{MHC}$ mismatches.

The team described the immunogenicity of $\mathrm{H}-\mathrm{Y}$ mHAs, antigens that are encoded by the $Y$ chromosome and therefore present only in males. These antigens can cause immune responses in female recipients. Transplants of cells derived from male mice survived long-term in male recipients but were rejected in female recipients of the same inbred strain ${ }^{3}$. Thus, the gender of the donors for cell products should be carefully considered.

To categorically avoid problems with immune rejection, many companies fov the generation of capabilities products. One way of ongous cell specific ESCs is via the technique of somatic cell nucleus transfer (SCNT), whic transfers the nucleus of a somatic (body) cell from the patient into an enucleated oocyte (an egg that has had its own

nucleus removed)

from a donor. After several days in which the oocyte divides, ESCs wi the patient's nuclear DNA can be isolated and expanded. However, these ESCs contain milochondria, small organelles that possess their own DNA, donor The immulogical releyance of this phenomenon was unknown until Dr Schrepfer and Dr Deuse discovered transplant-relevant $\mathrm{mHAs}$ in mitochondrial DNA $(m+D N A)^{4}$. Despite the ability to generate ESCs and various tissue-specific cell types possessing the patient-specific DNA, such cell products were subject to immune rejection if their mtDNA showed mismatches. The SCNT technology was shown not to circumvent the immune hurdle for $\mathrm{cel}$ transplantatio

AUTOLOGOUS INDUCED PLURIPOTENT STEM CELLS Autollogous induced pluripotent stem cells (iPSCs) are generated from a

Stem cell-derived products can induce an immune response, which ay limit the success of regenerative medicine approaches.

somatic cell donor. Derivatives from autologous IPSCs should thus not exp foreign antigens and should avoid At rest At

Dr Schrepfer and Dr Deuse carefully investigated how iPSC immunogenicity can be affected by reprogrammin expansion, and cell differentiation. The unexpected finding was that reprogramming and largethe emergence of mtDNA-encoded

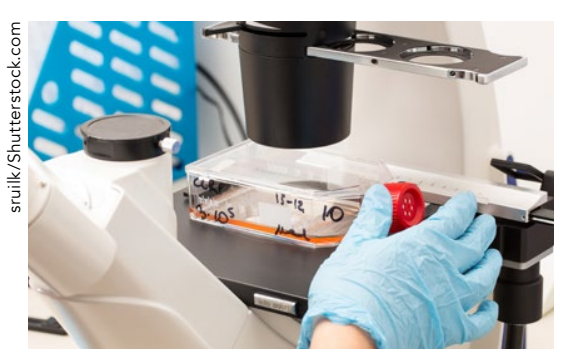

Stem cells hold great potential for treating neoantigens: these are antigens that developed during the process and cells. Mechanisms for the entic sterce of neontigens include mutations and (c) phenomena in all rapidly-$$
\text { proliferating tissues. }
$$

Mutation rates during been reported to be up to nine-fold higher han the mutation ate in resting cells. Furthermore, DNA by which a cell maintains the integrity of its genetic code, are less reliable for the mtDNA than for the nuclear DNA, and the mutation rate for mitochond DNA is ten- to twenty-fold higher immune surveillance duning in manipulations and expansion is believed 列 such antigens develop and allows for their unchecked amplification.

The mtDNA encodes only 13 protein subunits, but while a cell contains only two copies of its nuclear genome, it mitochondria that each contain dozens of copies of their that a cell can contain thousands of ce can contain thousands of copthis high number of copies, mtDNA mutations may generate a high number of mutant proteins. Once an increasing prevalence of neoantigen burden crosses n activation threshold of the immune system, a cytotoxic response is triggered 


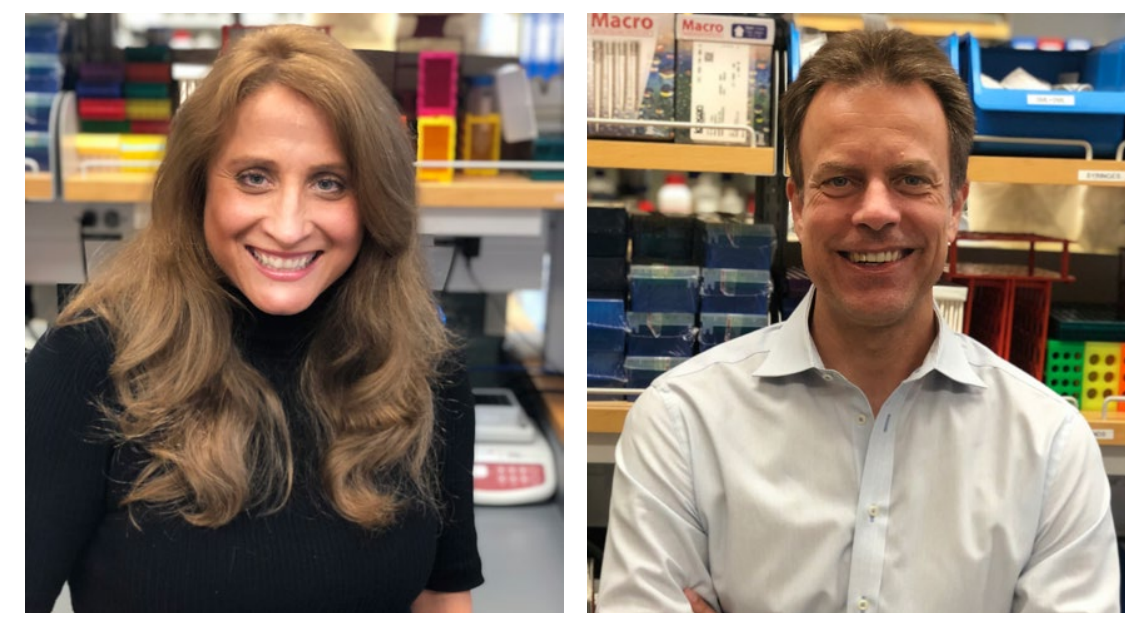

Dr Schrepfer and Dr Deuse's work is of critical imp
as it provides a strategy to overcome cell rejection.

The team generated truly hypoimmune stem cells that evade immune rejection.

rejected. Dr Schrepfer and Dr Deuse's experiments in both mice and humans DNA base (a phenomenon called sing nucleotide polymorphism, or SNP) is sufficient for the mutant protein to act as an antigen able to induce an immune response. Thorough quality control and routine screening for neoantigens during the manufacturing of autologous cell products is thus highly recommended. Reliable in vitro screening protocols have been described in DrSchrepfer's and Dr Deuse's articles.

\section{HYPO-IMMUNOGENIC IPSCS}

\section{Finally, Dr Schrepfer and Dr Deuse} established a novel approach to evasive PSCS, named "hypoimmmuneiPSCs". Such iPSCs do not induce any cellular immune response because they are barely visible to the immune system. If such hypoimmune iPSCs could be generated, they could serve as a sour for universally compatible cell and tissue grafts.

Their first strategy consisted of knocking down the expression of classIMHC in ESCs?. This knockdown resulted in less aggressive responses by the recipient immune system, and delayed the rejection of transplanted ESCs in mice. Although the work was performed before sophisticated gene editing were generated and differentiated into various different cell types. Rigorous in transplants in mice confirmed that this immune editing strategy successfully silenced all types of lymphoid and myeloid immune cells and hypoimm derivatives achieved long-term sunival in fully MHC-mismatched recipients. Hypoimmune stem cell derivatives were thus moved into a developmen phase looking towards potential clinical applications.

\section{A NEW NK CELL IMMUNE}

CHECKPOINT IS DISCOVERED

While immune-edited cells from other groups that also included the eliminatio of class IMHC remained susceptible to natural killer (NK) cell killing, the immune editing strategy by Dr Schrepfer and Dr closed this gap for immune evasion. NK cells will inherently kill MHC-

deficient target cells in the presence of inflammatory cytokines Such cytokines can be released by other immune cells in response to the transplant procedure or the graft cell. In-depth analysis of NK cell interactions with immune-edited cells revealed a new immune checkpoint?. NK cells were shown to be able to upregulate the immune checkpoint receptor signalregulatory protein-alpha, which delivers a strong inhibitory signal when engaging with its ligand CD47. An immune editing strategy including CD47 thus provides protection not only against phagocytes
but also NK cells.

\section{AN IMPACTFUL WORK}

Dr Schrepfer and Dr Deuse's findings have been highlighted in leading journals such as Nature and Science.9.13. Indeed, their work is of critical importance in the area of stem cell transplantation as it provides a strategy to overcome cell. rejection. The generation of hypoimmune iPSCs can pave the way toward the manufacturing of universally compatible cell products for regenerative medicine, a goal commonly referred to as the "holy grail" of stem cell immunobiology. This plattorm technology was exclusively licensed to Sana Biotechnology Inc, of which Dr Schrepfer is scientific founder and Head of the Hypoimmune Platform to make stem cell-derived therapies available

\section{Behind the Research

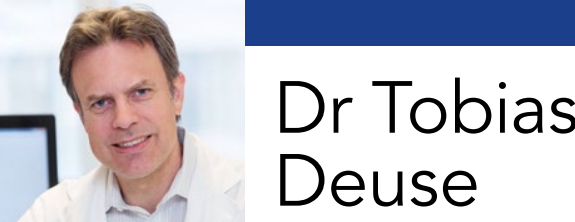 \\ Schrepfer}

Q

E: Sonja.schrepfer@ucsf.edu E: tobias.deuse@ucsf.edu T: +1 415.353 .8195

W: https://cardiacsurgery.ucsf.edu/meet-the-team/cardiac-surgery/tobias-deuse,-md.aspx W: https://tsilab.ucsf.edu/ W: https://adultctsurgery.ucsf.edu/conditions--procedures/minimally-invasive-mitral-valve-surgery.aspx

\section{References}

1. Swijnenburg R.J., Schrepfer S., Cao F., Pearl J. I., Xie X., Connolly
A. J, Robbins R., C., \& Wu J. C., (2008). In vivo imaging of embryonic stem cells reveals patterns of survival and immune rejection following transplantation. Stem cells and develop
https://doi.org/10.1089/scd.2008.0091

2. Swinenburirg R. J., Schrepfer S., Govaert J. A., Cao F., Ransohoff
K. Sheikh A. Y. Haddad M. Connolly A.J. Davis M. M. Robbins immunological rejection of human embryonic stem cell xenografts Proceedings ortice National Academy of Sciences of the United
States of America, 105(35), 12991-12996. https://doi.org/10.1073/ 3. HuX. 0805802105 G. Thuepers S., Kooreman N. G., Gravina A., Wang D., Tediashvil Deuse T. and Schrepfer S. (2020). H-Y- Incompatible Embryonic Stem Cell Transplantation causes rejection of nucleus matched cells. Stem

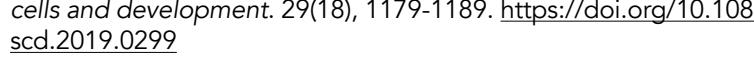

Greaves L. C., Alawi M. Grinewewald A. HuX. Hua X. Velden J., Reichenspurner H., Robbins R. C., Jaenisch R., Weissman I. mitochondria trigger an immune response in allogeneic hosts. Cell stem cell, 16(1), J3-38. hetps://dai.org//0.1016/1.stem.2014.11.003 5. Deuse T., Hu X., Agbor-Enoh S., Koch M., Spitzer M. H., Gravina
A., Alawi M., Marishta A., Peters B., Kosaloglu-Yalcin Z, Yang Y. Rajalingam R., Wang D., Nashan B., Kiefmann R., Reichenspurner
H., Valantine, Weissm H., Valantine H., Weissman I.L., \& Schrepfer S. (2019). De novo
mutations in mitochondrial DNA of iPSCS produce immunogenic mutations in mitochondrial DNA of
neoepitopes in mice and humans. Nature biotecthnology, $37(10)$, 1137-1144. https:///doi.org/10.1038/541587-019-0227-7 6. Deuse T., Seifert M., Phillips N., Fire A., Tyan D., Kay M., Tsao P.

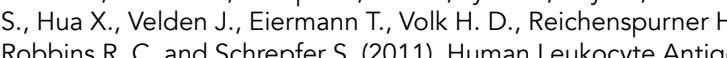
Knockdown Human Embryonic Stem Cells Induce Host Ignorance and Achieve Prolonged Xenogeneic Survival. Circulation. 124:S3-
S9. https:///doi.org/10.1161/CIRCULATIONAHA.111.020727 7. Deuse T., Hu X., Gravina A., Wang D., Tediashvili G., De C., WO. T,
Wahl A., Garcia J., Davis M. M., Lanier L. L. and Schrepfer S. (2019). Hypo-immunogenic i PSC-derivatives show long-term survival in fully immunocompetent allogeneic recipients. Nature Biotechnology/n
37(3):252-258. https://doi.org/ $10.1038 /$ s4 $1587-019-0016-3$ 8. Deuse T., Hu X., Agbor-Enoh S., Jang M.K., Alawi M., Saygi C., Gravina A., Tediashvili G., Nguyen V. Q. Liu Y., Valantine H., Lanier
LL Schrepfer S. The SIRPa-CD47 immune checkpoint in NK cells L.L., Schrepfer S. The SIRPa-CD47 i immune checkpoint in NK cells.
(2021). J Exp Med. ;218(3):220200339. doi: 10.1084/jism.2020033. still rejected. (2014). Natu 5 10. Dunham-Snary K. J. and Ballinger S. W. (2015). Mitochondrialnuclear DNA mismatch matters. Science, 349:1449-50.
11. European Perspectives. 2012. Circulation, 125:537-447. 11. European Perspectives. 2012. Circulation, $125: f 37-f 47$.
12. European Perspectives Highlights 2012 . Circulation, 2012:145-150.
13. European Perspectives in Cardiology. 2012. Circulation, 2012:37-47.

\section{Research Objectives}

DrSchrepfer and Dr Deuse demonstrated that allogeneic and autologous cell grafts can induce an immune response and
developed a new generation of cells to overcome immune rejection.

\section{Detail}

UCSF
Department of Surgery, Medical Sciences, S1207
500 Parnassus Ave 500 Parnassus Ave
San Francisco

San Francisco
CA 94143 USA

Bio
Sonja Schrepfer, M.D., Ph.D. is Professor of Surgery at UCSF and founder of the Transplant and Stem Cell Immunobiology (TSI) Lab. Tobias Deuse, M.D. is Professor of the Division of Adult
Cardiothoracic Surgery at UCSF. He holds the Julien I.E. Hoffman, M.D. Endowed Chair in Cardiac Surgery. He is the director of the Minimally invasive Cardiac Surgery Program an
the surgical director of the Transcatheter Valve Program. Funding

Disclosure

S.S. is scientific founder and Senior Vice President of Sana Neither a reagent nor any funding from Sana Biotechnology Inc. was used in the described studies. UCSF has filed paten

\section{Personal Response}

What are the next steps for your line of hypoimmunogenic
iPSCs to be used for therapeutic transplantation? iPSCs to be used for therapeutic transplantation?

II Since the development of this technology, it has
undergone thorough testing in several small and large undergone thorough testing in several small and large animal
models as well as human in vitro immune assays. The platform has been shown to very reliably generate immune evasive
stem cells as well as differentiated tissue cells. Now, the technology is being translated from research grade cells to in human clinical trials. We expect the first human studies to start enrolling following the submission of an IND, which
submission is expected as early as 2022 . 